Analysis

\title{
Beyond GDP: Measuring and achieving global genuine progress
}

\author{
Ida Kubiszewski a,*, Robert Costanza a, Carol Franco ${ }^{\text {b }}$, Philip Lawn ${ }^{\text {c }}$, John Talberth ${ }^{\text {d, }}$ \\ Tim Jackson ${ }^{\mathrm{e}}$, Camille Aylmer ${ }^{\mathrm{f}}$ \\ a Crawford School of Public Policy, Australian National University, Canberra, Australia \\ ${ }^{\mathrm{b}}$ Woods Hole Research Center, Falmouth, MA, United States \\ c Flinders University, Adelaide, Australia \\ d Center for Sustainable Economy, Washington DC, United States \\ e University of Surrey, Surrey, United Kingdom \\ ${ }^{\mathrm{f}}$ DuPont, Wilmington, DE, United States
}

\section{A R T I C L E I N F O}

\section{Article history:}

Received 6 December 2012

Received in revised form 25 April 2013

Accepted 30 April 2013

Available online $\mathrm{xxxx}$

\section{Keywords:}

Gross Domestic Product (GDP)

Genuine Progress Indicator (GPI)

Well-being

Happiness

Biocapacity

Ecological Footprint

Gini coefficients

Human Development Index (HDI)

Life Satisfaction

Beyond GDP

Global progress

\begin{abstract}
A B S T R A C T
While global Gross Domestic Product (GDP) has increased more than three-fold since 1950, economic welfare, as estimated by the Genuine Progress Indicator (GPI), has actually decreased since 1978 . We synthesized estimates of GPI over the 1950-2003 time period for 17 countries for which GPI has been estimated. These 17 countries contain 53\% of the global population and 59\% of the global GDP. We compared GPI with Gross Domestic Product (GDP), Human Development Index (HDI), Ecological Footprint, Biocapacity, Gini coefficient, and Life Satisfaction scores. Results show a significant variation among these countries, but some major trends. We also estimated a global GPI/capita over the 1950-2003 period. Global GPI/capita peaked in 1978, about the same time that global Ecological Footprint exceeded global Biocapacity. Life Satisfaction in almost all countries has also not improved significantly since 1975. Globally, GPI/capita does not increase beyond a GDP/capita of around $\$ 7000 /$ capita. If we distributed income more equitably around the planet, the current world GDP ( $\$ 67$ trillion/yr) could support 9.6 billion people at \$7000/capita. While GPI is not the perfect economic welfare indicator, it is a far better approximation than GDP. Development policies need to shift to better account for real welfare and not merely GDP growth.
\end{abstract}

(c) 2013 Elsevier B.V. All rights reserved.

\section{Introduction}

Nations need indicators that measure progress towards achieving their goals-economic, social, and environmental. Standard economic indicators like gross domestic product (GDP) are useful for measuring just one limited aspect of the economy-marketed economic activitybut GDP has been mistakenly used as a broader measure of welfare (Costanza et al., 2009; Stiglitz et al., 2010). GDP was never designed to measure social or economic welfare, and yet, today, it is the most commonly used indicator of a country's overall performance (Kuznets, 1934; Marcuss and Kane, 2007; McCulla and Smith, 2007).

GDP's current role poses a number of problems. A major issue is that it interprets every expense as positive and does not distinguish welfareenhancing activity from welfare-reducing activity (Cobb et al., 1995; Talberth et al., 2007). For example, an oil spill increases GDP because of the associated cost of cleanup and remediation, but it obviously detracts from overall well-being (Costanza et al., 2004). GDP also leaves out many components that enhance welfare but do not involve monetary

\footnotetext{
* Corresponding author. Tel.: +1 8607291126.

E-mail address: ida.kub@gmail.com (I. Kubiszewski).
}

transactions and therefore fall outside the market. For example, the act of picking vegetables from a garden and cooking them for family or friends is not included in GDP. Yet buying a similar meal in the frozen food aisle of the grocery store involves an exchange of money and a subsequent GDP increase. GDP also does not account for the distribution of income among individuals, which has a considerable effect on individual and social well-being (Wilkinson and Pickett, 2009).

A more comprehensive indicator would consolidate economic, environmental, and social elements into a common framework to show net progress (Costanza et al., 2004). A number of researchers have proposed alternatives to GDP that make one or more of these adjustments with varying components and metrics (Smith et al., 2013). Some have also noted the dangers of relying on a single indicator and have proposed a "dashboard" approach with multiple indicators.

One such alternative indicator that has been commonly used is the Genuine Progress Indicator (GPI). While GDP is a measure of current production, the GPI is designed to measure the economic welfare generated by economic activity, essentially counting the depreciation of community capital as an economic cost. The GPI is a version of the Index of Sustainable Economic Welfare (ISEW) first proposed in 1989 (Daly and Cobb, 1989). However, for the purposes of this paper we use GPI and 
ISEW interchangeably. GPI starts with Personal Consumption Expenditures (a major component of GDP) but adjusts them using 24 different components, including income distribution, environmental costs, and negative activities like crime and pollution, among others. GPI also adds positive components left out of GDP, including the benefits of volunteering and household work (Talberth et al., 2007). By separating activities that diminish welfare from those that enhance it, GPI better approximates sustainable economic welfare (Posner and Costanza, 2011). GPI is not meant to be an indicator of sustainability. It is a measure of economic welfare that needs to be viewed alongside biophysical and other indicators. In the end, since one only knows if a system is sustainable after the fact, there can be no direct indicators of sustainability, only predictors (Costanza and Patten, 1995).

Past national GPI studies have indicated that in many countries, beyond a certain point, GDP growth no longer correlates with increased economic welfare. An important function of GPI is to send up a red flag at that point. Since it is made up of many benefit and cost components, it also allows for the identification of which factors increase or decrease economic welfare. Other indicators are better guides of specific aspects. For example, Life Satisfaction is a better measure of overall self-reported happiness. By observing the change in individual benefit and cost components, GPI reveals which factors cause economic welfare to rise or fall even if it does not always indicate what the driving forces are behind this. It can account for the underlying patterns of resource consumption, for example, but may not pick up the self-reinforcing evolution of markets or political power that drives change.

\section{Critiques of GPI and Responses}

There have been a number of criticisms of GPI (Brennan, 2008; Harris, 2007; Neumayer, 2010). These include that the GPI: 1) uses inappropriate valuation methods to estimate some GPI items; 2) assumes that human-made capital and natural capital are substitutes; 3 ) includes some important welfare-related items but overlooks others, such as the benefits of political freedom; 4 ) is subjective in its choice of components to include and 5) lacks a solid theoretical basis. These criticisms are addressed in turn below.

The criticism regarding valuation methods refers to GPI's use of the cumulative cost of some environmental items, such as the cumulative cost of land degradation, lost wetlands, and long-term environmental damage. The reason why many GPI researchers have adopted a cumulative cost approach when calculating some environment costs relates to their 'strong sustainability' stance on GPI adjustments (Lawn, 2005). One of the essential aims of the GPI is to measure the economic welfare generated by economic activity. Economic activity, it should be recognized, is undertaken to generate a level of economic welfare greater than what can be provided by natural capital alone. For the GPI to properly reflect this reality, it is necessary to subtract the permanent loss of natural capital services.

There are many possible ways to measure these permanent losses. The most obvious way is to assume that the current welfare cost equates to the amount that existing people should be compensated for inheriting a diminished stock of natural capital. To be consistent with strong sustainability, appropriate compensation should approximate what it would have cost past generations to have kept the stock of natural capital intact. This is equivalent to the cumulative rather than annual cost of some environmental losses.

Another prominent criticism of the GPI is the view expressed by some observers that the calculation of the GPI implicitly assumes that humanmade capital and natural capital are substitutes. The basis of this criticism is that since the GPI involves the aggregation of diverse benefit and cost items into a single index, it is assumed that the additional benefits from a growing stock of human-made capital can perfectly substitute for the reduced benefits arising from a diminished stock of natural capital.

In responding to this criticism, it should be noted that if a benefit item rises by as much as another benefit item falls (or as much as a cost item increases), then the former has, at least for the time being, compensated for the latter. Thus, from a current welfare perspective, it is entirely correct to say that the former constitutes a substitute for the latter. However, this does not amount to saying that the total economic welfare currently being enjoyed is sustainable. To suggest otherwise is to wrongly confuse the substitutability of current welfare benefits with the substitutability of the capital that yields the welfare benefits.

For example, if the additional welfare benefits of more timber furniture exactly offset the immediate welfare losses of a cleared forest, current welfare remains unchanged. However, unlike forest, timber furniture cannot provide some of the source, sink, and life-support services that are needed to sustain future economic activity, including the production of new timber furniture. Thus, overall, current economic welfare has remained unchanged but the capacity for that economic welfare to be sustained has declined. Although the GPI reflects the former only, it should not be criticized simply because it does not fully reflect the latter since the GPI was never designed to be a strict measure of sustainability. It is for this reason that the GPI needs to be supplemented by biophysical indicators, such as the Ecological Footprint, to better indicate whether the economic welfare currently being enjoyed is sustainable.

Finally, an item such as the political freedom enjoyed by the nation's citizens is not included in the GPI because it is not the aim of the GPI to measure all welfare-related factors. As already stressed, the GPI is confined to measuring the total economic welfare generated by economic activity. It is confined in this way because one of the purposes of the GPI is to determine whether economic activity is increasing benefits more than costs-that is, to determine whether the marginal benefits of GDP growth are higher or lower than the marginal costs.

Political freedom is not a welfare benefit generated by economic activity. It should not, therefore, be incorporated into the GPI. If it so happens that greater political freedom has a positive impact on the economic welfare generated by economic activity, it is reflected in the many items that make up the GPI. Thus, it is incorrect to say that the GPI overlooks the positive effects of greater political freedom. To include a separate welfare item for political freedom would involve double-counting.

It is important to note that any aggregate indicator, including GDP, involves subjective judgments about what to include and how to weight different components.

\section{Countries for Which GPI Has Been Estimated}

GPI has been calculated for several countries and regions (Jackson and McBride, 2005; Jackson et al., 2008; Lawn and Clarke, 2008; Posner and Costanza, 2011). GPI is by no means a perfect indicator of wellbeing or progress, but it is a better approximation to economic welfare than GDP, which was never intended as a welfare measure. GPI estimates are often limited by the lack of appropriate social and environmental data compiled by national statistical agencies. So far, academic groups or NGOs have performed most GPI estimates. However, recently two state governments in the U.S. have adopted GPI as an official indicator, the states of Maryland and Vermont. In addition, the data necessary to estimate GPI is becoming more available in many countries and regions. For example, remote sensing data allow better estimates of changes in natural capital and surveys of individuals about their time use and Life Satisfaction are becoming more routine. The bottom line is that the costs of estimating GPI are not particularly high, the data limitations can be overcome, and it can be relatively easily estimated in most countries. Alternatively, a simplified version of GPI can also be calculated as an initial step in the process (Bleys, 2007).

This paper compares GDP/capita with GPI/capita for 17 countries with previously completed GPI/capita estimates. These 17 countries include $53 \%$ of the human population over five continents: Europe [Austria (Stockhammer et al., 1997), Belgium (Bleys, 2008), Germany, Italy, Netherlands (Rosenberg et al., 1995), Poland (Gil and Sleszynski, 2003), Sweden (Stymne and Jackson, 2000), United Kingdom (Jackson et al., 2008)], North America [United States (Talberth et al., 2007)], 
South America [Chile (Castaneda, 1999)], Oceania [Australia (Lawn, 2008a,b), New Zealand (Forgie et al., 2008)], and Asia [China (Wen et al., 2008), India (Lawn, 2008a,b), Japan (Makino, 2008), Thailand (Clarke and Shaw, 2008), Vietnam (Hong et al., 2008)]. We also compared GPI with several other well-known indicators for the same countries: Ecological Footprint, Biocapacity, Life Satisfaction, HDI, and the Gini coefficient as described below. These indicators were chosen as a comparison with GPI and GDP due to the availability of time series data and the international recognition they have received over the past few decades. Through this comparison we can identify trends in national progress and some of the key differences between the indicators.

We also synthesized the available country estimates of GPI to derive a global GPI estimate from 1950 to 2005 . While many uncertainties remain, including differences in methods and time periods covered in the different studies, discussed below, this derived estimate clearly shows a divergence between GDP and GPI after about 1978. In doing so, we also estimate a per capita GDP benchmark where per capita GPI at the global level begins to decline-where the costs of GDP growth begin to outweigh the benefits. Many other studies have pointed out the failings of GDP as an indicator of economic welfare (Easterlin, 1995), however, none have previously provided a global estimate of where economic welfare starts falling.

\section{Methods}

We performed a metadata analysis on the existing peer-reviewed literature that calculated time series GPI/capita and ISEW/capita at the national level. We found studies for 17 countries, for portions of the period between 1950 and 2010. However, methodological differences existed within the primary studies. For instance, many GPI studies used the Gini coefficient to estimate the inequality index. The U.K. and Swedish studies used the Atkinson index directly to estimate welfare loss. Some studies count cumulative GHG emission damage; others do not. However, we aggregated these studies with the assumption that they were sufficiently comparable on the basis that the underlying methodologies were similar.

We also assembled data on GDP/capita, HDI, Ecological Footprint/ capita, and Biocapacity/capita, for these 17 countries and the Gini coefficients and Life Satisfaction for a subset.

- Ecological Footprint: A measure of humanity's demand on nature. It measures how much biologically productive and mutually exclusive land area is necessary to provide humanity with the goods and services it requires with the current technology (Wackernagel and Rees, 1996; Wackernagel et al., 1999).

- Biocapacity: A measure of the biologically productive land available for producing resource materials and absorbing waste. It is calculated by considering not only the biological yield but also the technology and institutions available to take advantage of that yield (Wackernagel et al., 2004).

- Human Development Index (HDI): An index of life expectancy, education attained, and income per capita (McGillivray, 1991). The United Nations Development Programme (UNDP) developed HDI as a means of measuring development that included both social and economic progress (United Nations Development Programme, 1990).

- Life Satisfaction: A measure of subjective well-being based upon responses to questions about Life Satisfaction and personal happiness (Diener et al., 1999; Inglehart, 2000). Administered by the World Values Survey, and more recently by the Gallup Organization. Answers are typically from 0 to 10 , where 0 is dissatisfied and 10 is satisfied.

- Gini coefficient: A measure of income inequality. A Gini coefficient of zero indicates perfect equality while a coefficient of one indicates maximum inequality (Jacobson et al., 2005).
We indexed the data at year 1990 and created plots for each country as a means of comparing the changes in the indicators (Fig. 1).

We converted GPI/capita (or ISEW/capita) of each country to 2005 $\$$ U.S. by adjusting for currency and inflation. All GDP and GDP/capita data are in \$U.S. 2005 converted using Purchasing Power Parity (PPP). We then multiplied those by the population of the relevant years to produce GDP and GPI for each of the 17 countries for each year. Adding up those two indicators, we determined the total GDP and GPI for around $53 \%$ of the world's population and 59\% of the global GDP, depending on the data available in each year. Because the data available for the 17 countries did not all begin in the same year, the introduction or exclusion of a country has a significant effect on the GPI and GDP we calculated. These shifts between years can be seen in Fig. 2 .

Adjusting for this, we estimated a global GPI from our partial GPI based on the relationship between the partial GDP we calculated for the 17 countries and the actual world GDP for that year. Basically, due to the limited availability of GPI data, a population weighed sum was extrapolated from the 17 countries to estimate a global GPI. This was done by calculating the total GPI/capita and GDP/capita of each country and year in common units, aggregating them, and adjusting for population to estimate global GPI/capita and GDP/capita (Fig. 3).

For example, in 1969, we found that the partial GPI/capita was $\$ 10,794$ but it dropped dramatically to $\$ 4364$ by 1970 . This is due to the introduction of China's GPI/capita into the calculations, which only began in 1970 . We saw a similar drop that year in partial GDP/capita. However, since we knew the actual world GDP/capita for that year, we were able to use the relationship between the partial and the actual $\mathrm{GDP} /$ capita to revise our estimate of GPI/capita from the original estimate using the ratio: (Actual GPI/Estimate GPI) $=($ Actual GDP/Estimated GDP).

The resulting estimate is certainly not precise, but neither are multi-country aggregates of GDP time series, and the general trends in both are un-mistakable.

\section{Results}

We graphed the GPI/capita for all 17 countries on one graph (Fig. 4) (all GPI data were in \$U.S. 2005). Several of the 17 countries showed a similar trend of an increasing GPI/capita highly correlated with GDP/capita until at some point the GPI/capita either levels off or begins to decrease. This is primarily seen not only in European countries, but also China, and the U.S. We also graphed GDP/capita for all 17 countries (Fig. 5). For the majority of countries, GDP/capita has a continuous upward trend throughout the entire time period of 1950 through 2005.

The global GPI/capita and GDP/capita produce a similar trend (Fig. 3) over the early years of the study. Around 1978, the GPI/capita levels off and begins to decrease slightly, while GDP/capita continues to increase.

Indexed values (base year $1990=100$ ) for GDP, GPI (or ISEW in some cases), HDI, Ecological Footprint, and Biocapacity were calculated for the 17 countries, while the Gini coefficients and Life Satisfaction for some of them (Fig. 1).

When global GDP/capita is graphed versus global GPI/capita (Fig. 6), a strong linear correlation $\left(\mathrm{R}^{2}=0.98\right)$ is observed from about $\$ 3000$ to $\$ 7000 \mathrm{GDP} /$ capita. During this time, GPI/capita increases from its minimum to its maximum of about $\$ 3500$. After this point, GDP/capita continues to increase while $\mathrm{GPI} /$ capita diverges, showing a negative correlation $\left(\mathrm{R}^{2}=0.61\right)$.

\subsection{Results from the 17 Countries}

Fig. 4 shows trends in GPI/capita for all 17 countries for which GPI or ISEW has been estimated, along with trends in GDP/capita, Ecological Footprint, Biocapacity, HDI, and the Gini coefficient. Below we describe some of these trends. 
Australia experiences an almost parallel increase in GDP/capita and GPI/capita until approximately the mid-1970s. In the 1970s, a significant decline in income distribution was experienced in Australia, just as in many other developed countries around the world (Hamilton, 1999). Much of this decline in GPI/capita, after the mid-1970s, was due to transference of non-paid labor into the market. Between 1994 and 2006, GDP/capita rose sharply, however, GPI/capita did not experience a similar increase due to environmental and social losses Australia was experiencing at the same time (Lawn, 2008a,b). Although the Ecological Footprint/capita shows a slow decrease over the study period, Biocapacity/capita also decreases significantly. Life Satisfaction remains relatively constant, as does HDI, which shows a slight increase.
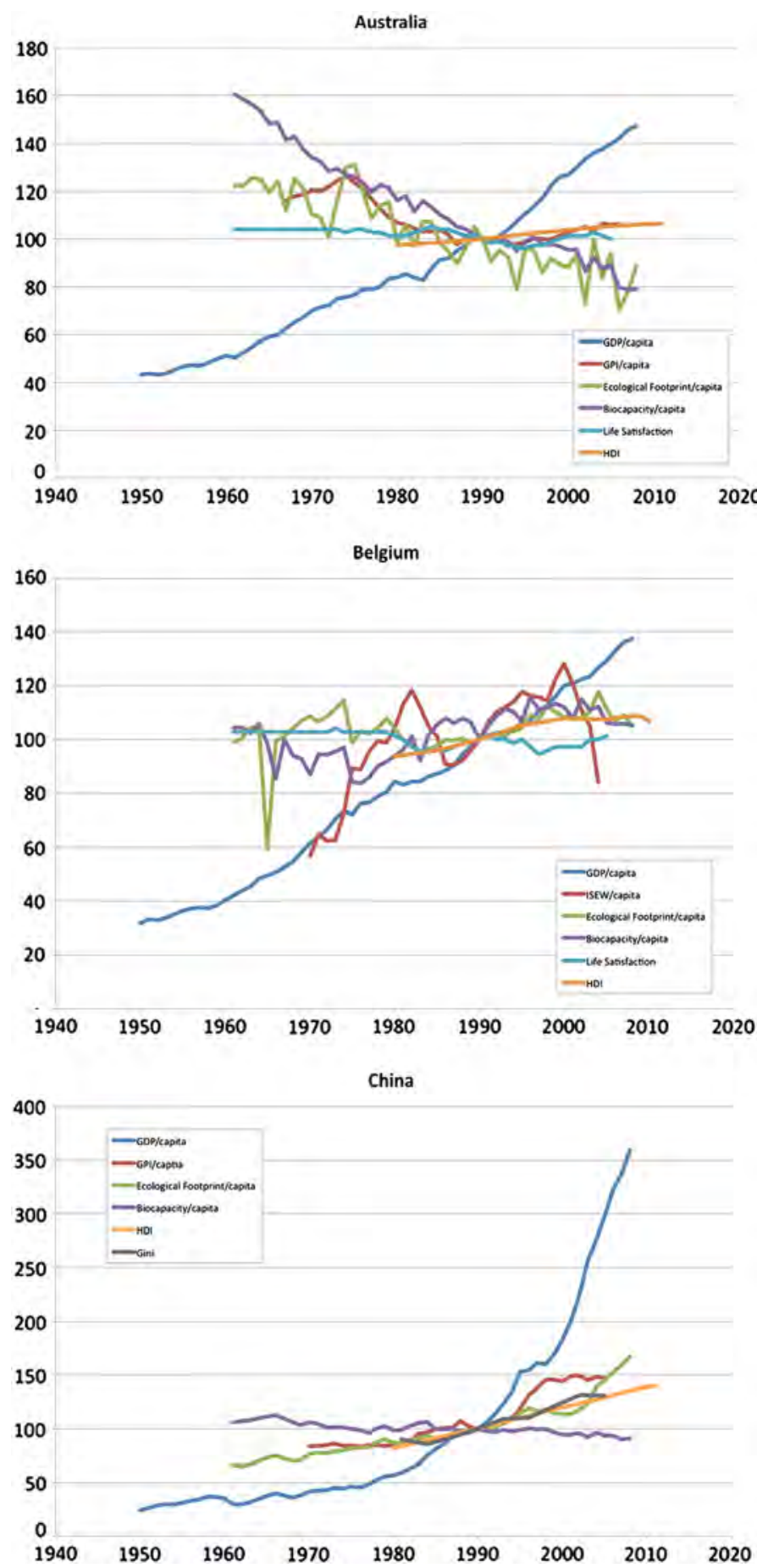

Austria experiences an almost parallel increase in GDP/capita and ISEW/capita until approximately 1980 . At which point, GDP/capita continues to increase while ISEW/capita levels off. This leveling off is primarily caused by long-term environmental damage, a worsening in income distribution, and a substitution between household production and private consumption (Stockhammer et al., 1997). The Ecological Footprint/capita increases significantly while Biocapacity/capita remains constant. The two intersect around 1970, the time at which Austria's footprint exceeds its Biocapacity. Life Satisfaction remains constant while HDI increases slightly.

Belgium shows a steady increase in GDP/capita through the study period. However, ISEW/capita is more volatile, experiencing two
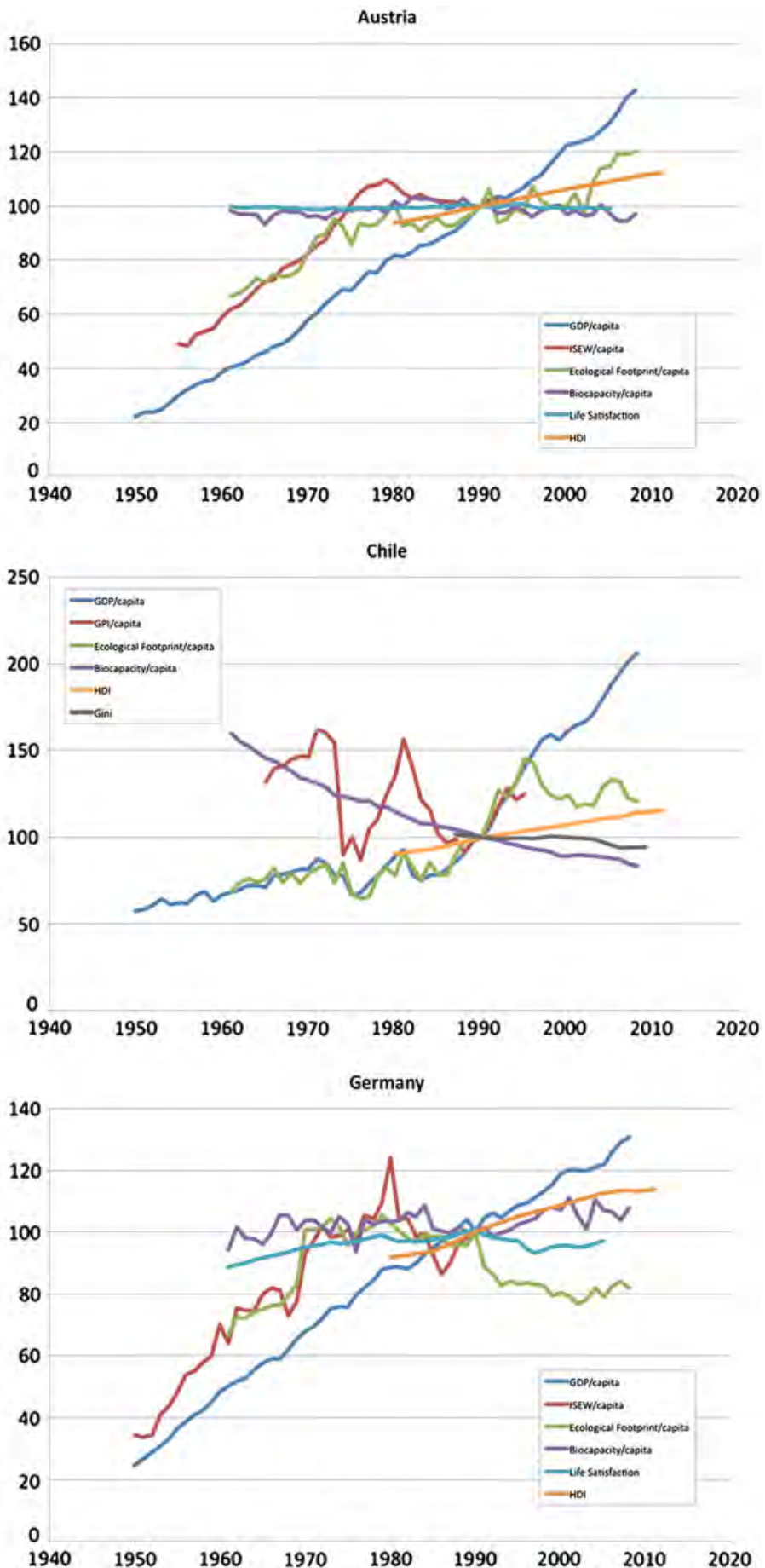

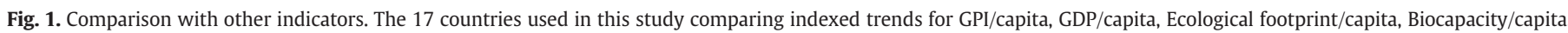
HDI, Life Satisfaction, and the Gini coefficient. All graphs are indexed to $1990=100$. 

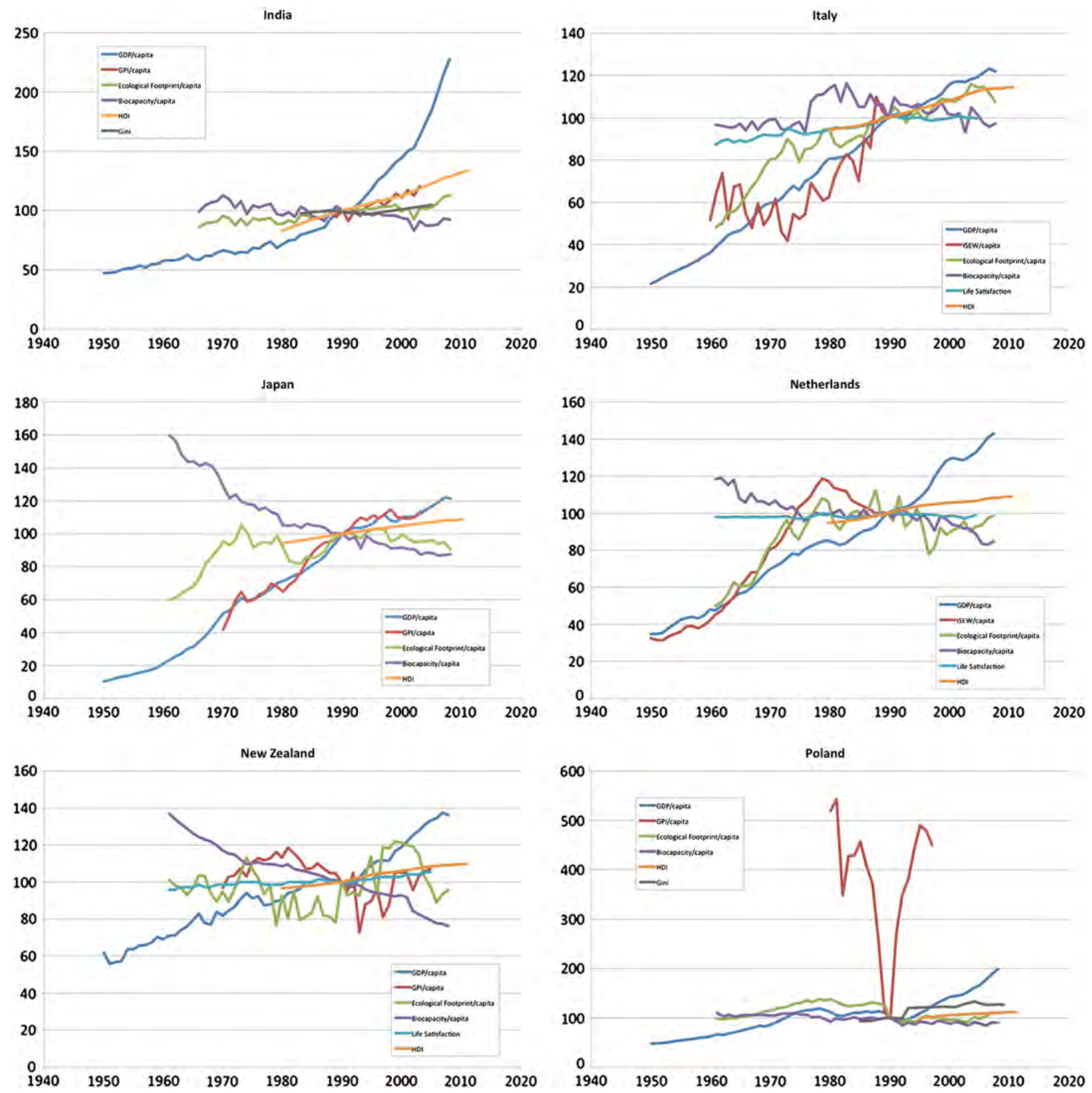

Fig. 1 (continued).

periods of steady increase ending with short periods of decline. The recession in ISEW in the 1980s was primarily due to a decrease in net capital growth, while the one in the 2000s is primarily due a decrease in Belgium's net international investment position (Bleys, 2008). The other four indices remain relatively constant. Ecological Footprint/ capita experiences a major dip around 1965 due to a calculation change and HDI increases slightly.

Chile's ISEW runs almost parallel to GDP until around 1985. After the 1982 recession, GDP/capita began to increase, almost double, while ISEW continued to decrease. Personal consumption caused the increase in GDP/capita, however, the accumulated environmental degradation, defensive costs, and depletion of natural capital decreased the populations' welfare overall. This dip in ISEW/capita in 1973 was the result of the military coup, which shifted the Chilean economy from very regulated to very deregulated (Raczynski and Romaguera, 1995). This coup increased privatization and decreased the role of the federal government, it also enacted market liberalization policy, including international trade. All these increased unemployment, inflation, debt, and interest rates, creating a recession and a decreasing of personal consumption (Castaneda, 1999). Ecological Footprint/capita increases approximately at the same rate as GDP/capita until about 1995 and then decouples from GDP/capita. Biocapacity/capita was on a continuous down-slope. HDI increased from medium level of development category while the Gini coefficient remains relatively constant.

China's most startling feature is the phenomenal growth rate of its $\mathrm{GDP} /$ capita in the post-1978 period, after the ascendance to power of 

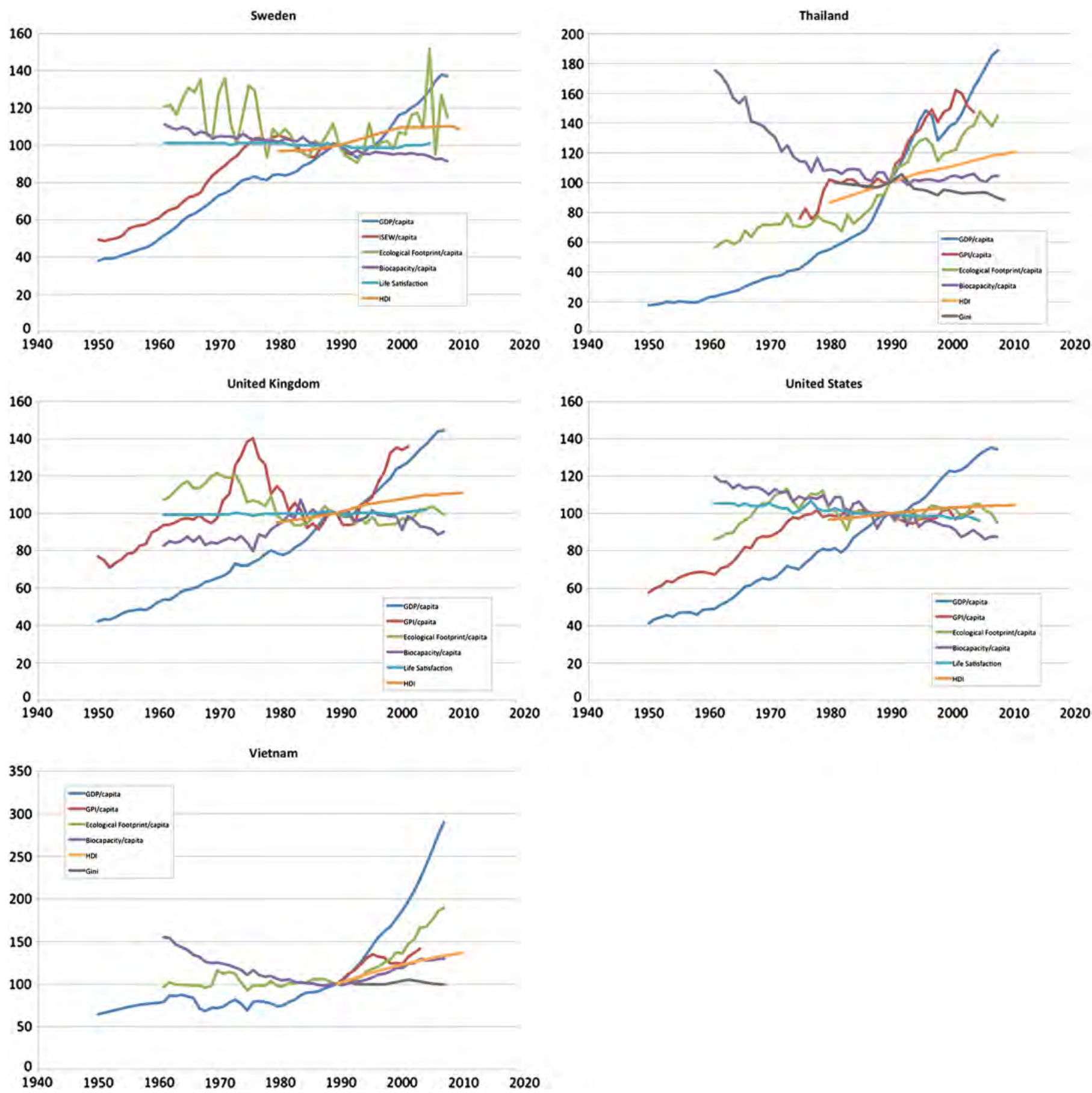

Fig. 1 (continued).

Deng Xiaoping. This 15-fold increase in GDP/capita since 1950 was primarily due to a radical shift in policy towards what was called a "socialist market economy", with increased foreign investment, exports to the global market and limited private competition. GPI/capita also improved during this period, especially in the 1990-1997 when $\mathrm{GPI} /$ capita growth rated equaled the growth rates of GDP/capita. However, after $1997 \mathrm{GPI} /$ capita leveled off even as GDP/capita continued its rapid rise. This divergence was due to the rapid increase of the external costs associated with rapid GDP growth-worsening income distribution (see the Gini coefficient), increasing crime, family breakdown, air and water pollution, and non-renewable resource depletion (Wen et al., 2008). China's HDI increased gradually over the period of record, from 1980 to 2010, driven by GDP/capita and spending on health and education. Biocapacity/capita and the Ecological Footprint/capita intersect at around 1990. Between 1981 and 2005, the Gini coefficient also continues to increase steadily, going from 0.29 to 0.42 , thus indicating a significant worsening of income distribution.

Germany: As with other European countries after the end of World War II and Marshall plan reconstruction, Germany's GDP/capita showed steady and rapid improvement over the whole period from 1950 to 2010. Germany's ISEW/capita was only estimated from 1950 to 1990 (this covered the Federal Republic of Germany only). Over this period it increased faster than GDP/capita from 1950 to 1980 and then declined from 1980 to 1990, but averaged over the whole period from 1950 to 1990 as it kept pace with increasing GDP/capita (Diefenbacher, 1994). Germany's Ecological Footprint/capita increased paralleling GDP/capita 


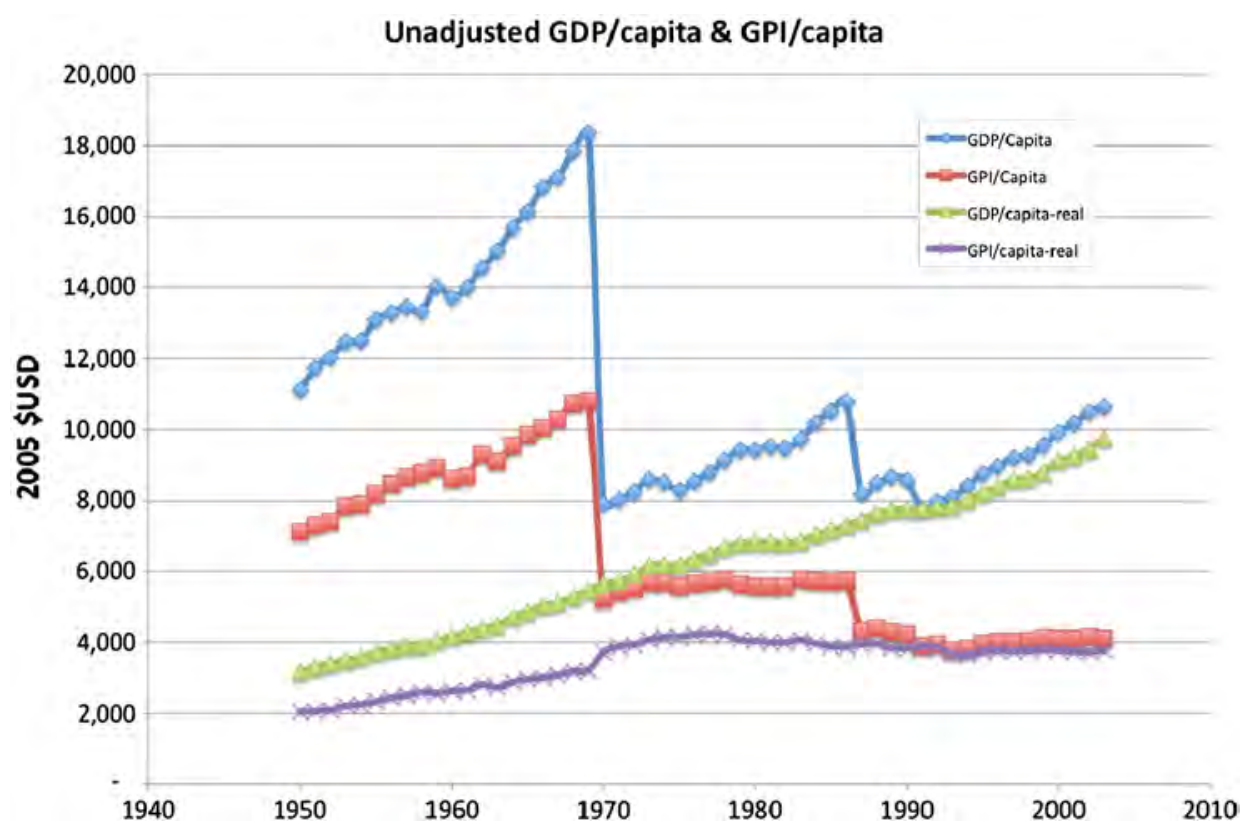

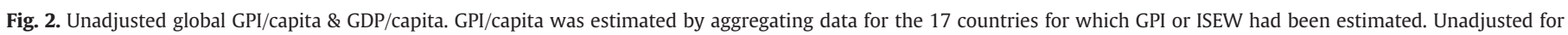
discrepancies caused by incomplete coverage by comparison with global GDP/capita data for all countries. All estimates are in 2005 US\$.

from 1950 to about 1970, after which increasing environmental awareness led to a decreasing footprint/capita. Biocapacity/capita remained relatively stable over the entire period. HDI increased gradually over the period of record, from 1980 to 2010, driven by GDP/capita and spending on health and education. Life Satisfaction in Germany increased from 1960 to 1980, was flat between 1980 and 1990, and decreased a bit after 1990 .

India's GDP/capita showed steady improvement over the period from 1950 to 1988 , after which GDP/capita accelerated at an amazing rate. India's GPI/capita was only estimated from 1985 to 2003. Over this period it increased, but at a much slower rate than GDP/capita. Interestingly, India's Gini coefficient decreased over this period due to the rapid growth of the middle class. In absolute terms, India's GDP/capita and
GPI/capita are still relatively low, however (Lawn, 2008a,b). India's Ecological Footprint/capita increased over the whole period, but not nearly as fast as GDP/capita. Biocapacity/capita decreased gradually over the entire period. HDI increased gradually over the period of record, from 1980 to 2010, driven by GDP/capita and spending on health and education.

Italy: After World War II and Marshall plan reconstruction, Italy's GDP/capita showed steady improvement over the whole period from 1950 to 2010. Italy's ISEW/capita was only estimated from 1960 to 1990 . Over this period it decreased from 1960 to 1970 , during a period of internal political turmoil, and then increased more rapidly than GDP/capita from 1970 to 1990. Italy's Ecological Footprint/capita increased paralleling GDP/capita and Biocapacity/capita remained fairly constant over the entire period. HDI increased gradually over the period

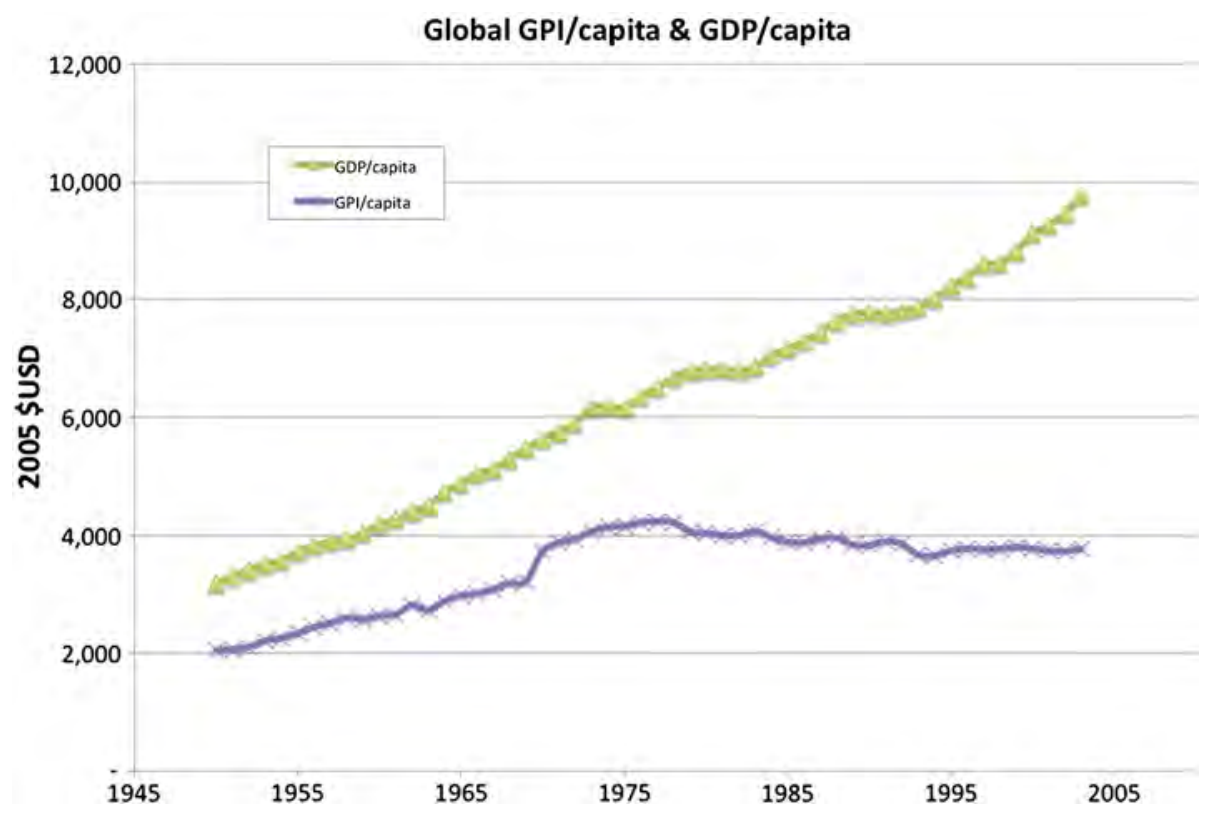

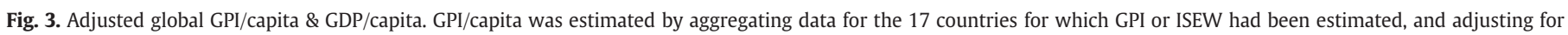
discrepancies caused by incomplete coverage by comparison with global GDP/capita data for all countries. All estimates are in 2005 US\$. 


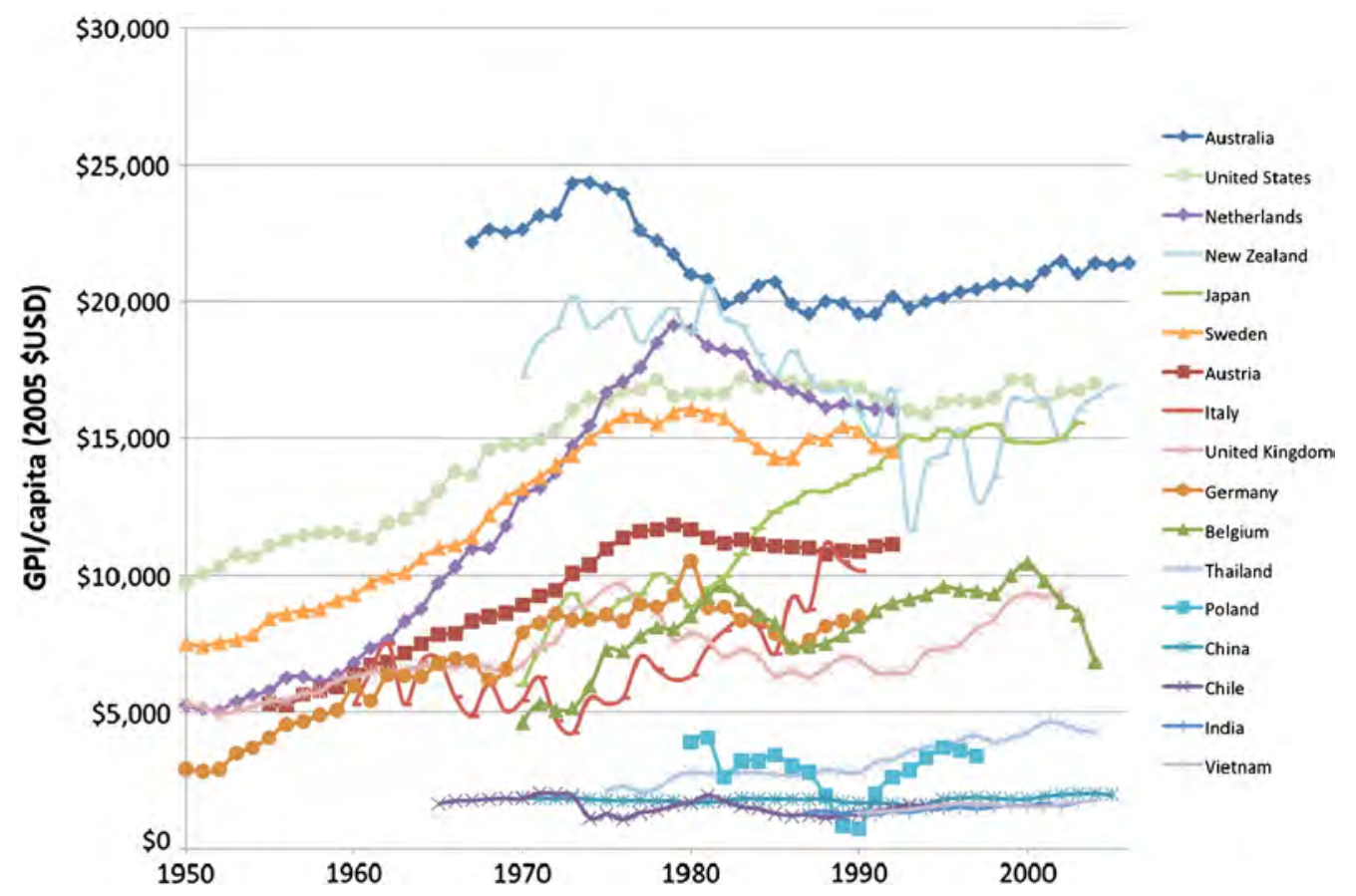

Fig. 4. GPI/capita. The GPI/capita for all 17 countries used in this. Estimates are from various sources noted in the text. All data are in 2005 US\$.

of record, from 1980 to 2010, driven by GDP/capita and increased spending on health and education.

Japan is unique in that it is the only developed country in which GPI/capita continues to follow GDP/capita. Prior to 1973, during the post-war growth, it saw a relatively quick increase in GPI/capita. However, when the first and second oil crises of 1973 and 1979 hit, $\mathrm{GPI} /$ capita became largely stagnant, as the country experienced its largest recession since WWII. However, to overcome this recession, the Japanese government created financial measures that brought upon an economic bubble, lasting from 1987 through about 1990. When this bubble popped another recession occurred. However, no major downturn in GPI/capita was observed as Japan relied heavily on domestic coal deposits during the 1960s and early 1970s, after which it shifted towards importing the majority of its natural resources, and towards oil and nuclear energy. This allowed Japan to decrease its pollution and use of domestic natural resources, allowing GPI/capita to retain some of its growth (Makino, 2008).

Netherlands: As with other European countries after the end of World War II and Marshall plan reconstruction, the Netherlands' $\mathrm{GDP} /$ capita showed steady improvement over the whole period from 1950 to 2010 . The Netherlands' ISEW/capita was only estimated from 1950 to 1990 . Over this period it increased at the same rate as GDP/capita from 1950 to 1960 and then more rapidly than GDP/capita from 1960 to 1978. The 1960s and 1970s were times of great social and cultural

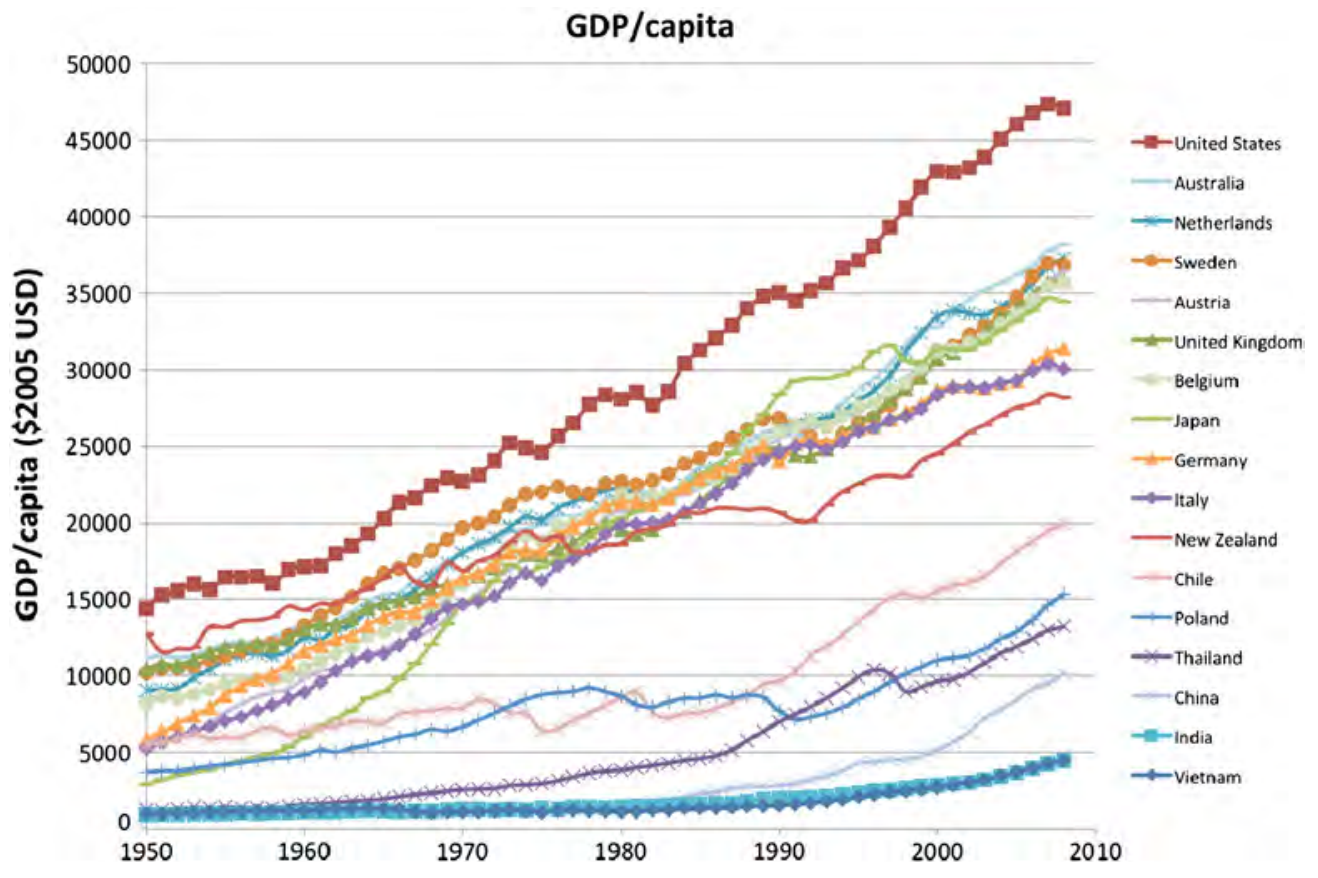

Fig. 5. GDP/capita. The GDP/capita for all 17 countries used in this study. All data in 2005 US\$. Source: Maddison (http://www.ggdc.net/MADDISON/oriindex.htm). 


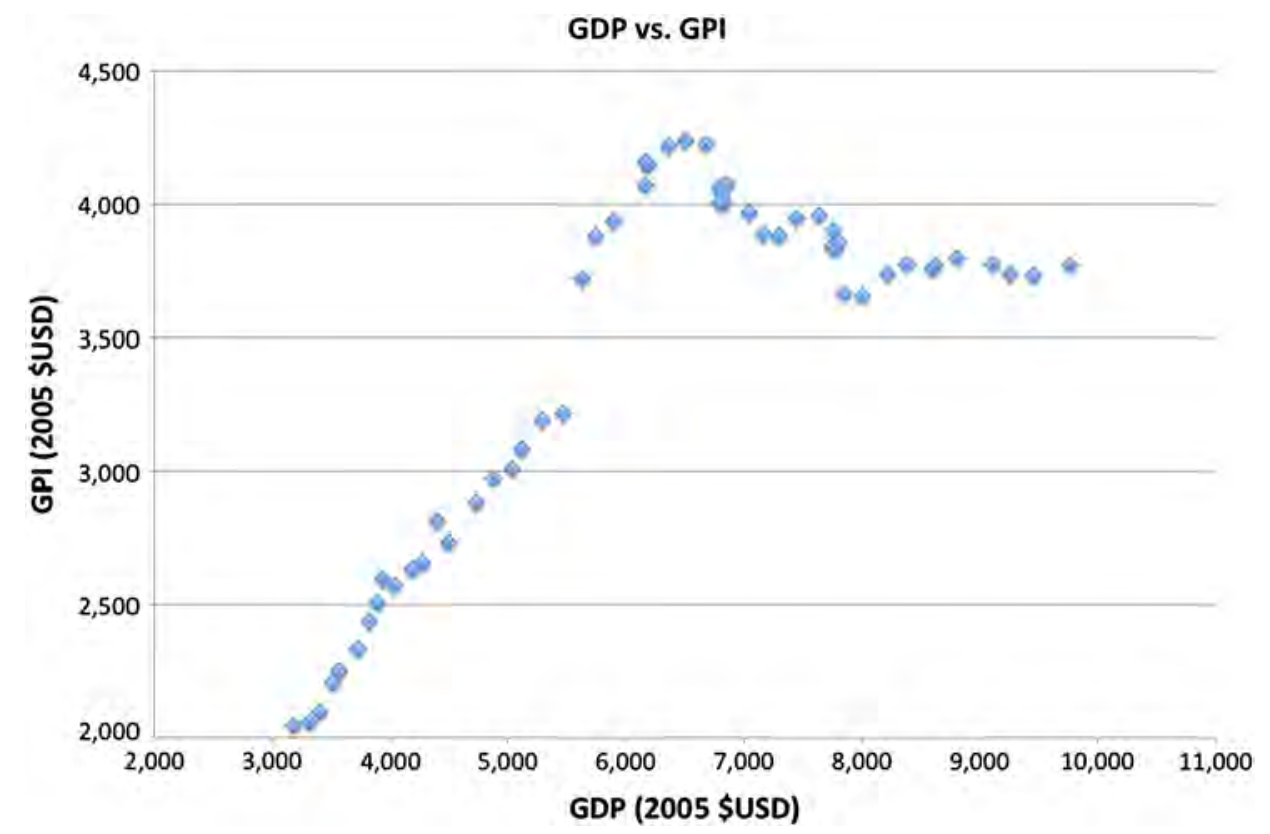

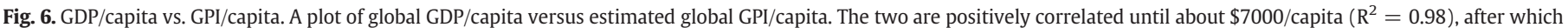
they diverge with a negative correlation $\left(\mathrm{R}^{2}=0.61\right)$. All data in 2005 US\$.

changes, with the construction of the welfare state, liberalization and decreasing income disparity. This trend reversed after 1978, but GPI/capita, averaged over the whole period from 1950 to 1990, kept pace with increasing GDP/capita (Rosenberg et al., 1995). The Netherlands' Ecological Footprint/capita increased paralleling GDP/capita from 1950 to about 1980, after which increasing environmental awareness led to a slightly decreasing Ecological Footprint/capita. Biocapacity/capita decreased gradually over the entire period. HDI increased gradually over the period of record, from 1980 to 2010, driven by GDP/capita and spending on health and education.

New Zealand experiences fluctuations throughout much of the time period for which GPI/capita has been calculated. Between about 1970 and 1984, New Zealand had a strong central government. It maintained a full employment economy, high wages, and social welfare systems. Between 1984 and 1994, major reforms were undertaken to make the economy more flexible and provide the country more of a global competitive advantage through deregulation. This move towards globalization also increased the use of non-renewable energy, greenhouse gas emissions, and unemployment. This can be seen by a decline in GPI/capita over this time period. Between 1994 and 2005, post-reform, New Zealand developed a liberalized and competitive economy, which increased employment and business confidence, but continued to put stress on the environment (Forgie et al., 2008). Some of the other indicators also experience fluctuations. The Ecological Footprint varies significantly between 1962 and 2008 but does not increase or decrease overall. Biocapacity decreases, while HDI and Life Satisfaction increase.

Poland experiences a major decrease in GPI between 1986 and 1989. This was a time of much instability within the government, when the Berlin Wall fell, and communism collapsed in Poland. However, the decrease in GPI/capita between 1986 and 1989, and then again between 1995and 1997, was also caused by an accumulated decrease in natural capital and household labor (Gil and Sleszynski, 2003). From 1961 through about 1980, Ecological Footprint/capita increased, however, it leveled off until about 1987, when it started decreasing. Such a decrease was caused by the instability in the government and the decrease in the availability of personal goods to consume. The decrease in Ecological Footprint/capita leveled off in early 1990 and only began increasing early 2000s. Biocapacity/capita remained constant through most of this period. HDI also remained relatively constant. The Gini coefficient, on the other hand, increased significantly in 1992 once communism fell.
Sweden's ISEW/capita was only estimated from 1950 to 1992. Over this period it increased at the same rate as GDP/capita from 1950 to 1970, increased faster than GDP/capita from 1970 to 75 but then leveled off from 1975 to 1992, following a leveling of GDP/capita. GDP/capita showed steady improvement over most of the period with recessions in the mid 1970s, coinciding with the Arab oil embargos, and late 1980s. Sweden's Ecological Footprint/capita was quite variable but relatively stable over the entire period and Biocapacity/capita decreased slowly over the entire period (Jackson and Stymne, 1996). HDI increased gradually over the period from 1980 to 1995 , driven by GDP/capita and spending on health and education, but leveled off after 1995 (albeit at a very high level). Life Satisfaction in Sweden was very constant over the whole period. Remember that these graphs are indices with 1990 as the base, so they show trends and changes. Sweden has relatively high numbers in absolute terms in GDP/capita, GPI/capita, and Life Satisfaction along with a low Gini coefficient (more equal distribution of income), meaning that adjusted Personal Consumption Expenditures are more equal to its base Personal Consumption Expenditures.

Thailand underwent four phases during the study period of 1975 through 2004. The first phase was a time when the Thai economy was transforming from one of agriculture to that of industry. This was a time of violent political upheavals, high inflation, and increasing fiscal deficit. Although, growth was seen in GPI/capita, it was moderate through 1981. Between 1981 and 1990, GPI/capita stagnated strongly due to the oil crisis experience a few years prior and the general global recession. However, the early 1990s brought on what was called the 'golden age'. However, this came to an end around 1997 when a financial crisis hit many of the Asian economies. Although the Thai economy managed to quickly recovered, GPI/capita has been variable (Clarke and Shaw, 2008). Similar pattern can be seen in the Ecological Footprint. Biocapacity/capital has, however, decreased. The HDI increased significantly during this time. Most interestingly, the Gini coefficient has decreased, which means that inequality within the population has decreased between 1980 and 2009.

United Kingdom's GPI/capita follows GDP/capita between 1952 and 1969, at which point GPI/capita experiences an intense spike, peaking in 1976, but dropping quickly to prior levels. This is a time when the Tory government of Edward Heath came into power, and began to cut social programs, which continued throughout the Margaret Thatcher period. Around 1993, GPI/capita began to increase again. GDP/capita, 
as in the United States, continued its steady increase throughout the entire study period (Jackson, 2004). Interestingly, Ecological Footprint/ capita slightly decreased while Biocapacity/capita slightly increased. Life Satisfaction remained constant while HDI increased slightly.

United States' GPI/capita shows a similar trend to that of the global GPI/capita. GPI/capita increases steadily until about 1978, at which point it flattens out. Between 1950 and 1978, GPI/capita increases similarly to GDP/capita. However, GDP/capita continues its steady increase through 2007 (Talberth et al., 2007). The Ecological Footprint/capita increases sharply until 1973 at which point it flattens out, even decreases to some extent. However, Biocapacity/capita decreases steadily over the entire study period as does Life Satisfaction. HDI, on the other hand, increases slightly.

Vietnam experienced post-war growth until about 1996 (years 1990 and 1991 were extrapolated to allow indexing). This growth was spurred by foreign investment into the economy and a state-controlled market economy but with greater private ownership, fewer price controls, and a public-private development of export processing zones. However, this economic growth caught up with Vietnam around 1996, when $\mathrm{GPI} /$ capita began to drop for a few years primarily due to environmental costs. The other indicators, such as the Ecological Footprint/capita were steady until about 1990, at which point they began to rise sharply (Hong et al., 2008). Interestingly, Biocapacity/capita decreases until about 1990 at which point it begins to increase again even as the Ecological Footprint/capita increases. HDI also increases significantly during the study period; however, the Gini coefficient remains relatively stable.

\section{Discussion}

China experienced rapid GDP/capita growth between 1950 and 2008 as it moved from an agrarian to an industrialized society. GPI/capita also increased during this time, albeit more slowly. After 1994, China joined the world market more completely and its GDP/capita, along with its $\mathrm{GPI} /$ capita, increased rapidly. However, this only lasted for about five years after which worsening income distribution (the Gini coefficient increased from 29 to 42 ) and high environmental externality costs became significant enough that they canceled out consumption-related gains. The change in these costs and benefits can be seen through the individual components that comprise GPI. Consequently, GPI/capita leveled off (Wen et al., 2008).

A similar trend is seen in India. A 1995 study by Manfred Max-Neef showed that the per capita GPI of wealthy nations started to fall when the per capita GDP reached around \$15,000-\$20,000 (Max-Neef, 1995). He concluded at the time that this constituted a 'threshold' level of per capita income (Lawn and Clarke, 2010). A subsequent study in 2008, showed that Thailand's per capita GPI started to fall when its per capita GDP reached $\$ 7500$ (Lawn and Clarke, 2008). For China, the threshold is at $\$ 5000$. One interpretation is that the threshold level of per capita income is contracting because poor nations are growing their GDP in a 'full' world (Costanza, 2008; Lawn and Clarke, 2010). Hence the marginal cost of GDP growth appears now to be much higher for poor nations at the same stage of the economic development process. We conclude that the ability of poor nations to increase their economic welfare may now be dependent upon rich countries abandoning their sole policy focus on GDP growth. This would provide the 'ecological space' for poor nations to experience a phase of welfare-increasing growth.

Japan on the other hand, is one of the only developed countries that experienced a continuous rise in GPI/capita between 1970 and 2003. Much of this is due to the rebuilding after World War II, but is particularly striking in view of Japan's 'lost decade' of faltering economic growth. As in China, much of this growth was based on intense natural resource use. In recent years, starting around 1990, the GPI rate of increase has diminished due to environmental degradation and societal inequality (Makino, 2008). Fig. 1 also shows that Ecological Footprint/capita and Biocapacity/ capita for Japan intersect around 1990. This means that after that point, Japan began using resources faster than it was generating them.
However, Japan is a very heavy importer of raw materials and therefore its own environmental costs have not risen significantly (Clarke, 2007; Makino, 2008). This creates a problem for GPI since it does not handle transboundary issues well. It also underscores the case for estimating a global GPI since an undervaluation of environmental costs in one country is counterbalanced by overvaluation in others.

The graph for the United Kingdom (Fig. 1) seems to show much variation over the course of 52 years. However, because these are indexed graphs, showing only trends, we see that the change in actual GPI/capita is small throughout that period, which can be seen more clearly in Fig. 4. GDP/capita has been increasing steadily over that time period (Fig. 5) (Jackson et al., 2008) while GPI showed increases and decreases due to changes in government policies.

The United States (Fig. 1) shows GPI/capita and GDP/capita increasing at a relatively similar rate until about 1979 at which point GDP/capita continues to increase while GPI/capita flattens out. This occurred for reasons similar to those in other countries: a rising of income inequality combined with environmental and social costs rising faster than consumption-related benefits.

Interestingly, HDI and Life Satisfaction do not change much within any of the 17 countries (see Supplementary information). In three of our four example countries, Japan, the United Kingdom, and the United States, the Ecological Footprint/capita remains significantly higher than Biocapacity/capita.

There is also a general trend that appears from approximately 1950 until around 1975 where the GPI/capita for the majority of countries is increasing. Much of this is due to the rebuilding effort after World War II when consumption and built capital were the limiting factors for improving well-being in many countries and environmental externalities had not yet become significant. However, around the mid-to late 1970s, much of the infrastructure was rebuilt while rising income inequality and increasing external environmental costs canceled the growth in consumption-related benefits, causing GPI/capita to level off.

\section{Global Estimates}

This same pattern can be seen in the global estimate of GPI/capita (Fig. 3). At the global level, the decrease begins to occur around 1978. This decrease has occurred while global GDP/capita has steadily increased-in some countries drastically, such as China and India. This shows that although GDP growth is increasing benefits, they are being outweighed by rising inequality of income and increases in costs.

GPI is not a perfect measure of overall human well-being since it emphasizes economic welfare and leaves out other important aspects of well-being. It is, however, a far better indicator than GDP, which is not designed to measure welfare at all. Societal well-being or welfare ultimately depends on the underlying stocks of natural, human, built, and social capital, and because the GPI makes additions and deductions to GDP to reflect net contributions to these stocks it is a far superior measure of economic welfare than GDP (Vemuri and Costanza, 2006). The disconnection between GPI and GDP, beginning in 1978, shows the aspects of our well-being that have been declining since that time. It also provides focus areas in which societal improvement is necessary.

Fig. 6 shows that globally GPI/capita peaks at around \$7000 GDP/ capita. This estimate excludes any African countries. Because most African nations are poor, and given the GPI results for China (where the GPI started declining at a per capita GDP of \$5000), a threshold per capita GDP value of $\$ 7000$ is therefore a conservative one.

Until this $\$ 7000 \mathrm{GDP} /$ capita peak, the GPI/capita and GDP/capita are highly correlated $\left(\mathrm{R}^{2}=0.98\right)$. This is consistent with some studies showing subjective well-being leveling of after around $\$ 7000 \mathrm{GDP} /$ capita (Deaton, 2008; Inglehart, 1997). It is also interesting that there is a negative correlation $\left(\mathrm{R}^{2}=0.61\right)$ between GDP/capita and GPI/capita after about $\$ 7000 \mathrm{GDP} /$ capita. This is also consistent with the 'threshold hypothesis' proposed by Manfred Max-Neef, which states that: "for every society there seems to be a period in which economic growth 
(as conventionally measured) brings about an improvement in the quality of life, but only up to a point-the threshold point-beyond which, if there is more economic growth, quality of life may begin to deteriorate" (Max-Neef, 1995).

We can use this GDP/capita maximum from Fig. 6 to estimate the maximum global GDP/capita consistent with a non-declining GPI/capita. Assuming better access to family planning services in high population growth nations, it should be possible to limit the global population to no more than 9.6 billion people. This is the number of people that could be equitably supported by the current global GDP/capita of $\$ 67$ trillion at approximately $\$ 7000$ per person. Variations in income would need to exist between and within nations, however these disparities should be much smaller than they are today.

Many scientists argue that even current consumption levels are not sustainable (Daily and Ehrlich, 1992; Rees, 2006). The global Ecological Footprint/capita exceeded global Biocapacity/capita around 1978. As of 2011 , humans were using $135 \%$ of the resources that can be sustainably generated in one year (Ecological Footprint, 2011). Based on this estimate of the degree of current overshoot, we conclude that a $35 \%$ increase in the technical efficiency of global production would allow the global Ecological Footprint to be brought back within global Biocapacity. This degree of technical improvement appears to be feasible (von Weizsacker et al., 2009). If this degree of technical improvement could be achieved, then the global GDP of $\$ 67$ trillion that is required to provide a welfare-maximizing GDP/capita of $\$ 7000$ for 9.6 billion people may be sustainable. Once reached, continuing improvements in environmental protection, full employment (distributional equity), and product quality would allow the GPI/capita to rise without the need for further increases in global GDP. It may be possible to increase economic welfare without having to grow GDP, as recently seen in the state of Maryland (King, 2012).

Although stopping GDP growth in developed countries will not by itself cause economic welfare to rise, rising environmental costs are directly related to the rise in the rate of resource use and waste generation, which is due to the growth in GDP, despite technological advances. Environmental costs could be reduced by reducing material and fossil energy throughput to the global economy. Some of this may come with efficiency advances, but some will result in reductions in GDP-recognizing that this may actually be welfare enhancing. In addition, a more equitable distribution of income and opportunities will allow the welfare contribution of a given level of consumption to be increased. Welfare benefits can also be increased through the production of higher quality, longer lasting goods and the social capital benefits of a fairer and more just society.

\section{Conclusion}

It is increasingly recognized that GDP was never designed as a measure of economic welfare and GDP growth is no longer an appropriate national policy goal (Costanza et al., 2009; Stiglitz et al., 2010). GPI, while certainly not perfect, is a far better approximation of economic welfare than GDP. By assembling GPI estimates and other indicators for 17 countries representing $53 \%$ of the global population, we have been able to show significant trends and differences, and to estimate a global GPI. By this measure, economic welfare at the global scale has not been improving since 1978 .

If we hope to achieve a sustainable and desirable future, we need to rapidly shift our policy focus away from maximizing production and consumption (GDP) and towards improving genuine human well-being (GPI or something similar). This is a shift that will require far more attention to be paid to environmental protection, full employment, social equity, better product quality and durability, and greater resource use efficiently (i.e., reducing the resource intensity per dollar of GDP). These changes are clearly within our grasp, and are underway in several countries and regions. Alternative measures of progress, like GPI, are useful to help chart and guide the course if appropriately used and understood.

\section{References}

Bleys, B., 2007. Simplifying the index of sustainable economic welfare: methodology, data sources and a case study for The Netherlands. International Journal of Environment, Workplace and Employment 3 (2), 103-118.

Bleys, B., 2008. Proposed changes to the index of sustainable economic welfare: an application to Belgium. Ecological Economics 64 (4), 741-751 (http://www. sciencedirect.com/science/article/pii/S0921800907005137).

Brennan, A.J., 2008. Theoretical foundations of sustainable economic welfare indicatorsISEW and political economy of the disembedded system. Ecological Economics 67 (1), 1-19.

Castaneda, B.E., 1999. An index of sustainable economic welfare (ISEW) for Chile. Ecological Economics 28 (2), 231-244.

Clarke, M., 2007. Is the Genuine Progress Indicator really genuine? Considering well-being impacts of exports and imports. International Journal of Environment, Workplace and Employment 3 (2), 91-102.

Clarke, M., Shaw, J., 2008. Genuine progress in Thailand: a systems-analysis approach. In: Lawn, P.A., Clarke, M. (Eds.), Sustainable Welfare in the Asia-Pacific: Studies Using the Genuine Progress Indicator. Edward Elgar Publishing Cheltenham, UK, pp. 126-152.

Cobb, C. Halstead, T. Rowe, J., 1995. If the GDP is up, why is America down? The Atlantic Monthly 276, 59-78.

Costanza, R., 2008. Stewardship for a "full” world. Current History 107 (705), 30-35.

Costanza, R., Patten, B.C., 1995. Defining and predicting sustainability. Ecological Economics 15 (3), 193-196 (<Go to ISI>://WOS:A1995TM30700002).

Costanza, R., Erickson, J., Fligger, K., Adams, A., Adams, C., Altschuler, B., Balter, S., Fisher, B., Hike, J., Kelly, J., Kerr, T., McCauley, M., Montone, K., Rauch, M., Schmiedeskamp, K., Saxton, D., Sparacino, L., Tusinski, W., Williams, L., 2004. Estimates of the Genuine Progress Indicator (GPI) for Vermont, Chittenden County and Burlington, from 1950 to 2000. Ecological Economics 51 (1-2), 139-155.

Costanza, R., Hart, M., Posner, S., Talberth, J., 2009. Beyond GDP: The Need for New Measures of Progress.

Daily, G.C., Ehrlich, P.R., 1992. Population, sustainability, and Earth's carrying capacity. Bioscience 42 (10), 761-771.

Daly, H.E., Cobb Jr., J.B., 1989. For the Common Good: Redirecting the Economy Toward Community, the Environment, and a Sustainable Future. Beacon Press, Boston.

Deaton, A., 2008. Income, health, and well-being around the world: evidence from the Gallup World Poll. The Journal of Economic Perspectives 22 (2), 53-72.

Diefenbacher, H., 1994. The index of sustainable economic welfare in Germany. In: Cobb, C., Cobb, J. (Eds.), The Green National Product. University of the Americas Press, New York

Diener, E., Suh, E.M., Lucas, R.E., Smith, H.L., 1999. Subjective well-being: three decades of progress. Psychological Bulletin 125 (2), 276.

Easterlin, R.A., 1995. Will raising the incomes of all increase the happiness of all? Journal of Economic Behavior Organization 27 (1), 35-47 (http://www.sciencedirect.com/ science/article/pii/016726819500003B)

Ecological Footprint, 2011. Earth Overshoot Day, Sept 27 2011. Retrieved 10 June, 2012, from http://www.footprintnetwork.org/en/index.php/GFN/blog/today_is_earth_ overshoot_day1.

Forgie, V., McDonald, G., Zhang, Y., Patterson, M., Hardy, D., 2008. Calculating the New Zealand genuine progress indicator. In: Lawn, P.A., Clarke, M. (Eds.), Sustainable Welfare in the Asia-Pacific: Studies Using the Genuine Progress Indicator. Edward Elgar Publishing, Cheltenham, UK, pp. 126-152.

Gil, S., Sleszynski, J., 2003. An index of sustainable economic welfare for Poland. Sustainable Development 11 (1), 47-55.

Hamilton, C., 1999. The genuine progress indicator methodological developments and results from Australia. Ecological Economics 30 (1), 13-28.

Harris, M., 2007. On income, sustainability and the 'microfoundations' of the Genuine Progress Indicator. International Journal of Environment, Workplace and Employment 3 (2), 119-131.

Hong, V.X.N., Clarke, M., Lawn, P., 2008. Genuine progress in Vietnam: the impact of Doi Moi reforms. In: Lawn, P.A., Clarke, M. (Eds.), Sustainable Welfare in the Asia-Pacific: Studies Using the Genuine Progress Indicator. Edward Elgar Publishing, Cheltenham, UK, pp. 299-330.

Inglehart, R., 1997. Modernization and postmodernization. Cultural, Political and Economic Change in 43 Societies.Princeton University Press, Princeton.

Inglehart, R., 2000. Globalization and postmodern values. The Washington Quarterly 23 (1), 215-228.

Jackson, T., 2004. Chasing Progress-Beyond Measuring Economic Growth.

Jackson, T., McBride, N., 2005. Measuring Progress? A Review of 'Adjusted' Measures of Economic Welfare in Europe.

Jackson, T., Stymne, S., 1996. Sustainable Economic Welfare in Sweden: A Pilot Index 1950-1992.

Jackson, T., McBride, N., Abdallah, S., Marks, N., 2008. Measuring Regional Progress: Regional Index of Sustainable Economic Well-being (R-ISEW) for All the English Regions.

Jacobson, A., Milman, A.D., Kammen, D.M., 2005. Letting the (energy) Gini out of the bottle: Lorenz curves of cumulative electricity consumption and Gini coefficients as metrics of energy distribution and equity. Energy Policy 33 (14), 1825-1832.

King, K., 2012. Maryland GPI grows more than 2 percent last year. Retrieved 02/18/2013, from http://news.maryland.gov/dnr/2012/10/01/maryland-gpi-grows-more-than-2percent-last-year/.

Kuznets, S., 1934. National Income, 1929-1932.

Lawn, P.A., 2005. An assessment of the valuation methods used to calculate the Index of Sustainable Economic Welfare (ISEW), Genuine Progress Indicator (GPI), and Sustainable Net Benefit Index (SNBI). Environment, Development and Sustainability 7 (2), 185-208. http://dx.doi.org/10.1007/s10668-005-7312-4. 
Lawn, P.A., 2008. Genuine progress in Australia: time to rethink the growth objective. In: Lawn, P.A., Clarke, M. (Eds.), Sustainable Welfare in the Asia-Pacific: Studies Using the Genuine Progress Indicator. Edward Elgar Publishing, Cheltenham, UK, pp. 91-125.

Lawn, P.A., 2008. Genuine progress in India: some further growth needed in the immediate future but population stabilisation needed immediately. In: Lawn, P.A., Clarke, M. (Eds.), Sustainable Welfare in the Asia-Pacific: Studies Using the Genuine Progress Indicator. Edward Elgar Publishing, Cheltenham, UK, pp. 91-125.

Lawn, P.A., Clarke, M., 2008. Sustainable Welfare in the Asia-Pacific: Studies Using the Genuine Progress Indicator. Edward Elgar Publishing, Cheltenham, UK.

Lawn, P., Clarke, M., 2010. The end of economic growth? A contracting threshold hypothesis. Ecological Economics 69 (11), 2213-2223.

Makino, M., 2008. Genuine progress in Japan and the need for an open economy GPI. In: Lawn, P.A., Clarke, M. (Eds.), Sustainable Welfare in the Asia-Pacific: Studies Using the Genuine Progress Indicator. Edward Elgar Publishing, Cheltenham, UK, pp. 153-189.

Marcuss, D., Kane, R.E., 2007. US national income and product statistics born of the Great Depression and World War II. Bureau of Economic Analysis: Survey of Current Business 87 (2), 32-46.

Max-Neef, M., 1995. Economic growth and quality of life: a threshold hypothesis. Ecological Economics 15 (2), 115-118.

McCulla, S.H., Smith, S., 2007. Measuring the Economy: A Primer on GDP and the National Income and Product Accounts.

McGillivray, M., 1991. The human development index: yet another redundant composite development indicator? World Development 19 (10), 1461-1468 (http://www. sciencedirect.com/science/article/pii/0305750X9190088Y).

Neumayer, E., 2010. Weak Versus Strong Sustainability: Exploring the Limits of Two Opposing Paradigms. Edward Elgar, Cheltenham.

Posner, S.M., Costanza, R., 2011. A summary of ISEW and GPI studies at multiple scales and new estimates for Baltimore City, Baltimore County, and the State of Maryland. Ecological Economics 70 (11), 1972-1980 (http://www.sciencedirect.com/science/ article/pii/S0921800911001935).

Raczynski, D., Romaguera, P., 1995. Chile: poverty, adjustment, and social policies in the 1980s. In: Lusting, N. (Ed.), Coping with Austerity. The Brookings Institution, Washington DC, pp. 275-333.

Rees, W.E., 2006. Ecological Footprints and Biocapacity: Essential Elements in Sustainability Assessment. Renewables-based Technology.John Wiley \& Sons, Ltd 143-157.

Rosenberg, D., Oegema, P., Bovy, M., 1995. ISEW for the Netherlands: Preliminary Results and Some Proposals for Further Research. IMSA, Amsterdam.
Smith, L.M., Case, J.L., Smith, H.M., Harwell, L.C., Summers, J.K., 2013. Relating ecosystem services to domains of human well-being: foundation for a U.S. index. Ecological Indicators 28, 79-90.

Stiglitz, J.E., Sen, A., Fitoussi, J.P., 2010. Mismeasuring Our Lives: Why GDP Doesn't Add Up. The New Press, New York.

Stockhammer, E., Hochreiter, H., Obermayr, B., Steiner, K., 1997. The index of sustainable economic welfare (ISEW) as an alternative to GDP in measuring economic welfare. The results of the Austrian (revised) ISEW calculation 1955-1992. Ecological Economics 21 (1), 19-34.

Stymne, S., Jackson, T., 2000. Intra-generational equity and sustainable welfare: a time series analysis for the UK and Sweden. Ecological Economics 33, 219-236.

Talberth, J., Cobb, C., Slattery, N., 2007. The Genuine Progress Indicator 2006: A Tool for Sustainable Development.

United Nations Development Programme, 1990. Human Development Report 1990 Oxford University Press.

Vemuri, A.W., Costanza, R., 2006. The role of human, social, built, and natural capital in explaining life satisfaction at the country level: toward a National Well-Being Index (NWI). Ecological Economics 58 (1), 119-133.

von Weizsacker, E.U., Hargroves, C., Smith, M.H., Desha, C., Stasinopoulos, P., 2009. Factor Five: Transforming the Global Economy through 80\% Improvements in Resource Productivity. Routledge.

Wackernagel, M., Rees, W.E., 1996. Our Ecological Footprint: Reducing Human Impact on the Earth. New Society Pub.

Wackernagel, M., Onisto, L., Bello, P., Callejas Linares, A., Susana López Falfán, I., Méndez García, J., Isabel Suárez Guerrero, A., Guadalupe Suárez Guerrero, M. 1999. National natural capital accounting with the ecological footprint concept Ecological Economics 29 (3), 375-390 (http://www.sciencedirect.com/science/article/ pii/S0921800998900635).

Wackernagel, M., Monfreda, C., Schulz, N.B., Erb, K.-H., Haberl, H., Krausmann, F. 2004 Calculating national and global ecological footprint time series: resolving conceptual challenges. Land Use Policy 21 (3), 271-278 (http://www.sciencedirect.com/science/ article/pii/S0264837703000863).

Wen, Z., Yang, Y., Lawn, P.A., 2008. From GDP to GPI: quantifying thirty-five years of development in China. In: Lawn, P.A., Clarke, M. (Eds.), Sustainable Welfare in the Asia-Pacific: Studies Using the Genuine Progress Indicator. Edward Elgar Publishing, Cheltenham, UK, pp. 228-259.

Wilkinson, R.G., Pickett, K., 2009. The Spirit Level: Why Greater Equality Makes Societies Stronger. Bloomsbury Press, New York. 